\title{
(6) OPEN ACCESS \\ Tobacco industry response to menthol cigarette bans in Alberta and Nova Scotia, Canada
}

\author{
Jennifer Brown, ${ }^{1}$ Teresa DeAtley, ${ }^{1}$ Kevin Welding, ${ }^{1}$ Robert Schwartz, ${ }^{2,3}$ \\ Michael Chaiton, ${ }^{2,4}$ Deirdre Lawrence Kittner, ${ }^{5}$ Joanna E Cohen ${ }^{1,6}$
}

${ }^{1}$ Institute for Global Tobacco Control, Johns Hopkins Bloomberg School of Public Health, Baltimore, Maryland, USA

${ }^{2}$ Ontario Tobacco Research Unit, University of Toronto, Toronto, Ontario, Canada ${ }^{3}$ Social and Behavioral Health Sciences Division, Dalla Lana School of Public Health,

University of Toronto, Toronto, Ontario, Canada

${ }^{4}$ Epidemiology Division, Dalla Lana School of Public Health, University of Toronto, Toronto, Ontario, Canada

${ }^{5}$ Campaign for Tobacco-Free Kids, Washington, District of Columbia, USA

${ }^{6}$ Department of Health, Behavior and Society, Johns Hopkins Bloomberg School of Public Health, Baltimore, Maryland, USA

\section{Correspondence to} Jennifer Brown, Institute for Global Tobacco Control, Johns Hopkins Bloomberg School of Public Health, 2213 McElderry St, Fourth Floor, Baltimore, MD 21205, USA;

jbrow212@jhu.edu

Received 3 April 2016 Accepted 22 June 2016 Published Online First 19 July 2016

\section{CrossMark}

To cite: Brown J, DeAtley T, Welding $\mathrm{K}$, et al. Tob Control 2017:26:e71-e74.
Menthol cigarettes are associated with increased initiation and progression to regular smoking and decreased likelihood of smoking cessation. ${ }^{1-8}$ Menthol smokers are more likely to be women and adolescents in several countries. ${ }^{9}$ The Conference of the Parties to the Framework Convention on Tobacco Control recommend that Parties regulate ingredients that make cigarettes more palatable, including flavouring substances like menthol. ${ }^{10}$ The Canadian province Nova Scotia became the first jurisdiction to implement a ban on menthol tobacco products in May 2015, and the province of Alberta followed in September 2015. ${ }^{11}$ These regulations extended existing provincial bans on the sale of flavoured tobacco products to include menthol flavoured tobacco products, with the exception of pipe tobacco and some cigars. Additional Canadian provinces, Brazil, Ethiopia, Turkey and the European Union have passed regulations to ban menthol tobacco products. ${ }^{11}$

As jurisdictions (including cities, states/provinces and countries) consider bans on menthol tobacco products, real-life contextual data on the industry response to such bans can be helpful in formulating effective bans. For example, when misleading descriptors on tobacco packaging such as 'light' and 'low tar' were prohibited, the tobacco industry continued to communicate those same misleading health messages to the consumer using colour or other descriptors. ${ }^{12}{ }^{13}$ Industry tactics to undermine the effectiveness of health warnings on tobacco packaging have included the use of promotional packaging and altered pack size. ${ }^{14} 15$ Drawing on a sample of cigarette packs purchased in Alberta and Nova Scotia, Canada, we describe the industry response to a ban on menthol tobacco products.

Between September and December 2015, we purchased a sample of cigarette packs from two major cities in Alberta preban and postban (422 packs) and Nova Scotia postban (76 packs). At major retailers, store clerks were asked for menthol and green packs preban and menthol, menthol replacement, green and new packs to the market postban. At one store in each city, all unique packs of cigarettes available were purchased. A pack was considered unique if it differed in at least one exterior pack feature including brand name, colours, design elements or cellophane. In total, 63 stores were visited and 35 purchases were made. Using qualitative content analysis, we identified menthol packs as well as descriptors and pack features that may connote 'menthol replacement' packs. While the regulations include prohibitions on menthol tobacco products with a few exceptions, our analysis focused on cigarettes.

\section{COMPLIANCE}

Findings suggest that tobacco manufacturers are complying with the 'letter of the law'. No cigarette packs labelled as 'menthol' were purchased in Alberta or Nova Scotia postban. However, among packs purchased postban in Alberta, brands identified as menthol preban were repackaged to connote products that were menthol replacements.

\section{PACK COLOUR AND BRAND NAME DESCRIPTORS}

We categorised packs as 'menthol replacements' if they largely maintained the same colour and design as menthol packs sold preban. Among the packs collected preban, all packs labelled as menthol featured green as a prominent colour. Menthol replacement packs continued to display green as a prominent colour. The only change across all menthol replacement packs, when compared to menthol packs purchased preban, was the substitution of the word 'menthol' with the descriptor 'green' (figure 1). Additionally, $87.3 \%$ of menthol replacement packs were wrapped in cellophane displaying the phrase 'smooth taste [redesigned] without menthol' (figure 2). One retailer showed us business-to-business (B2B) marketing materials demonstrating the shift from old to new packs (figure 3).

\section{MARKET RESPONSE}

A total of 199 menthol packs from 14 brand families, owned by three parent companies (Philip Morris International (PMI), Japan Tobacco International and British American Tobacco), were purchased in Alberta preban; postban, 63 menthol replacement packs from four brand families owned by one parent company (PMI) were purchased.

Menthol replacement packs were not found in Nova Scotia postban. This may be due to the difference in population sizes between Alberta (4.1 million) and Nova Scotia ( $<1$ million). ${ }^{16}$ The tobacco industry may have considered Alberta as a more desirable test market than Nova Scotia for selling a redesigned product prior to the roll out of menthol bans in other Canadian provinces. There could also be a temporal element-retailers in Nova Scotia mentioned that new tobacco products are introduced in the province several months later than other provinces. In addition, tobacco companies may have speculated that the potential for further regulation to close existing loopholes would be greater in Nova Scotia than in Alberta. 

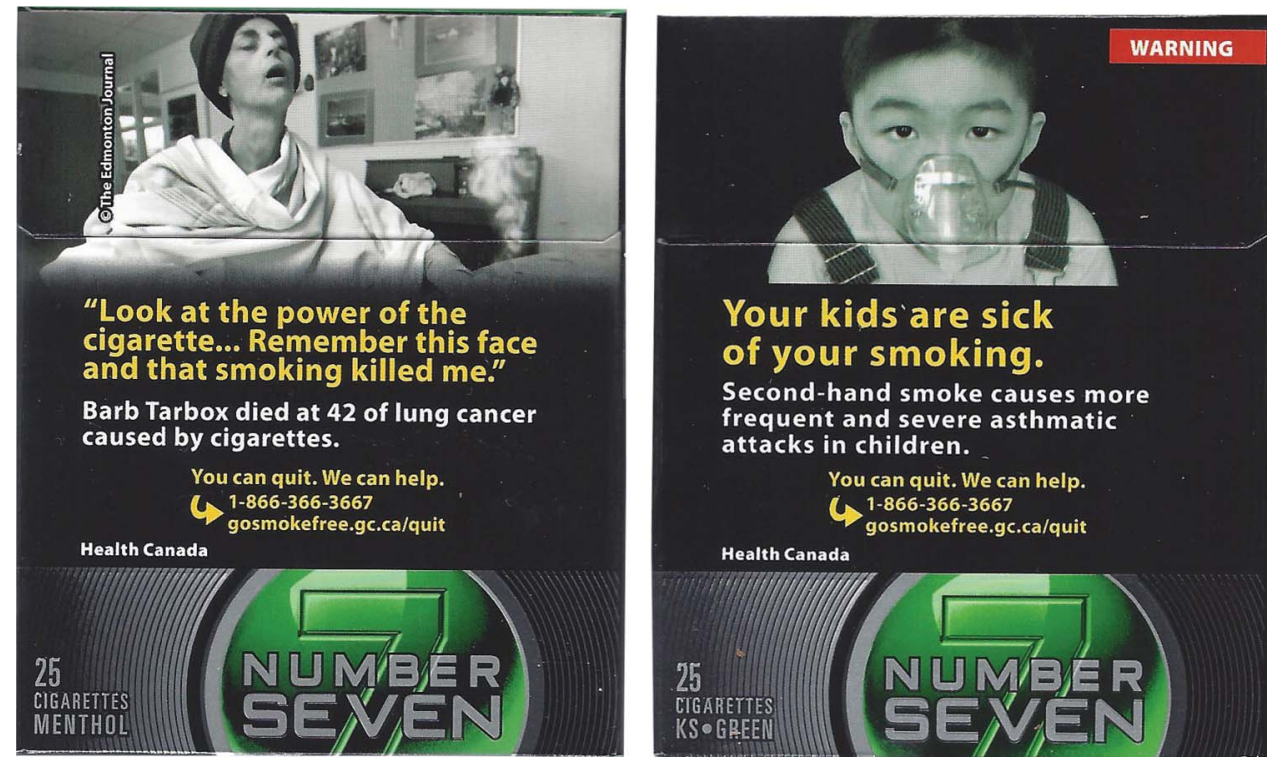

Figure 1 Left: Number Seven menthol pack preban with the 'menthol' descriptor at the bottom left; Right: Number Seven menthol replacement pack postban with the 'green' descriptor at the bottom left.

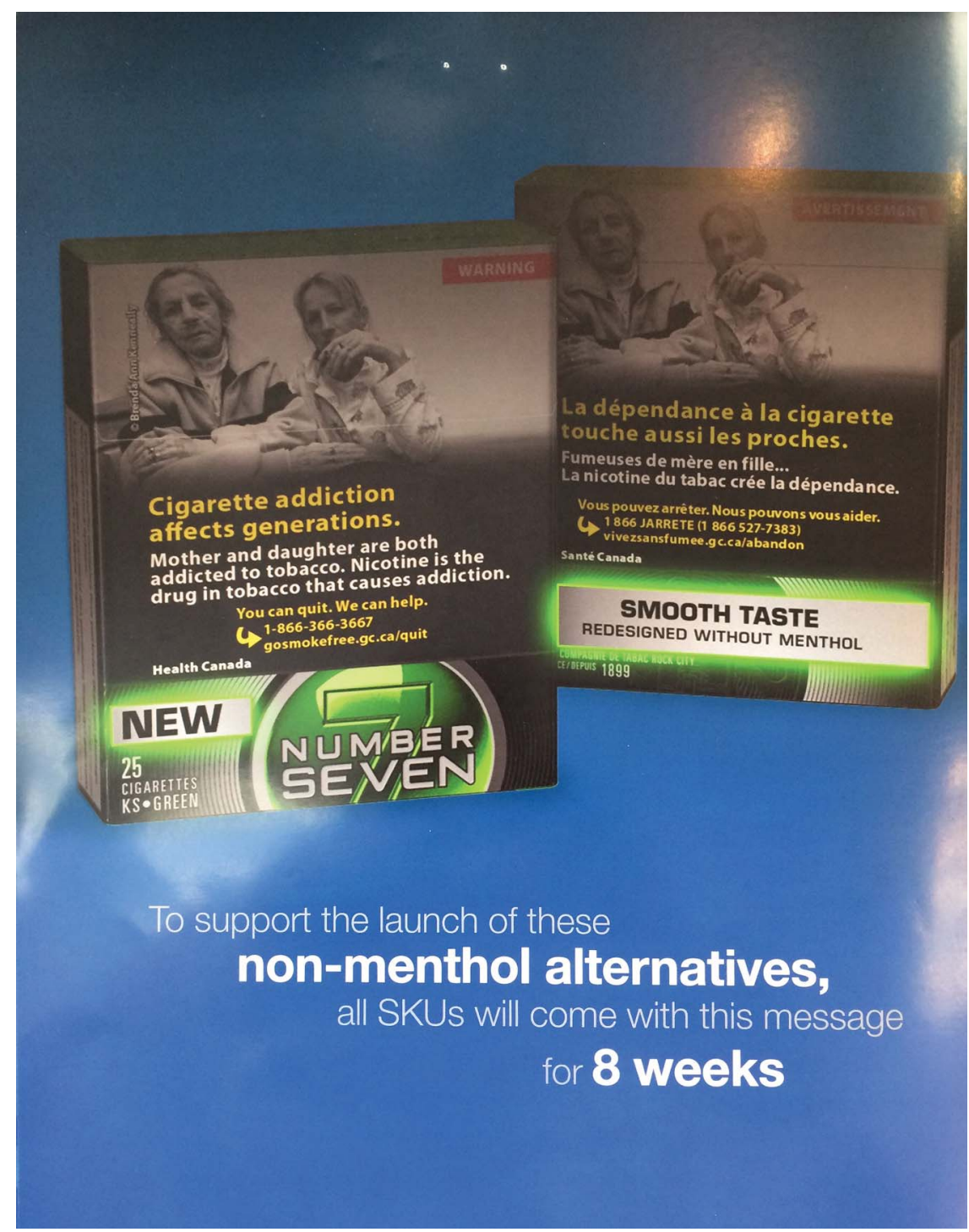

Figure 2 Business-to-business marketing materials from Rothman, Benson \& Hedges (owned by Philip Morris International), highlighting the message on cellophane wrapping on new packs. 


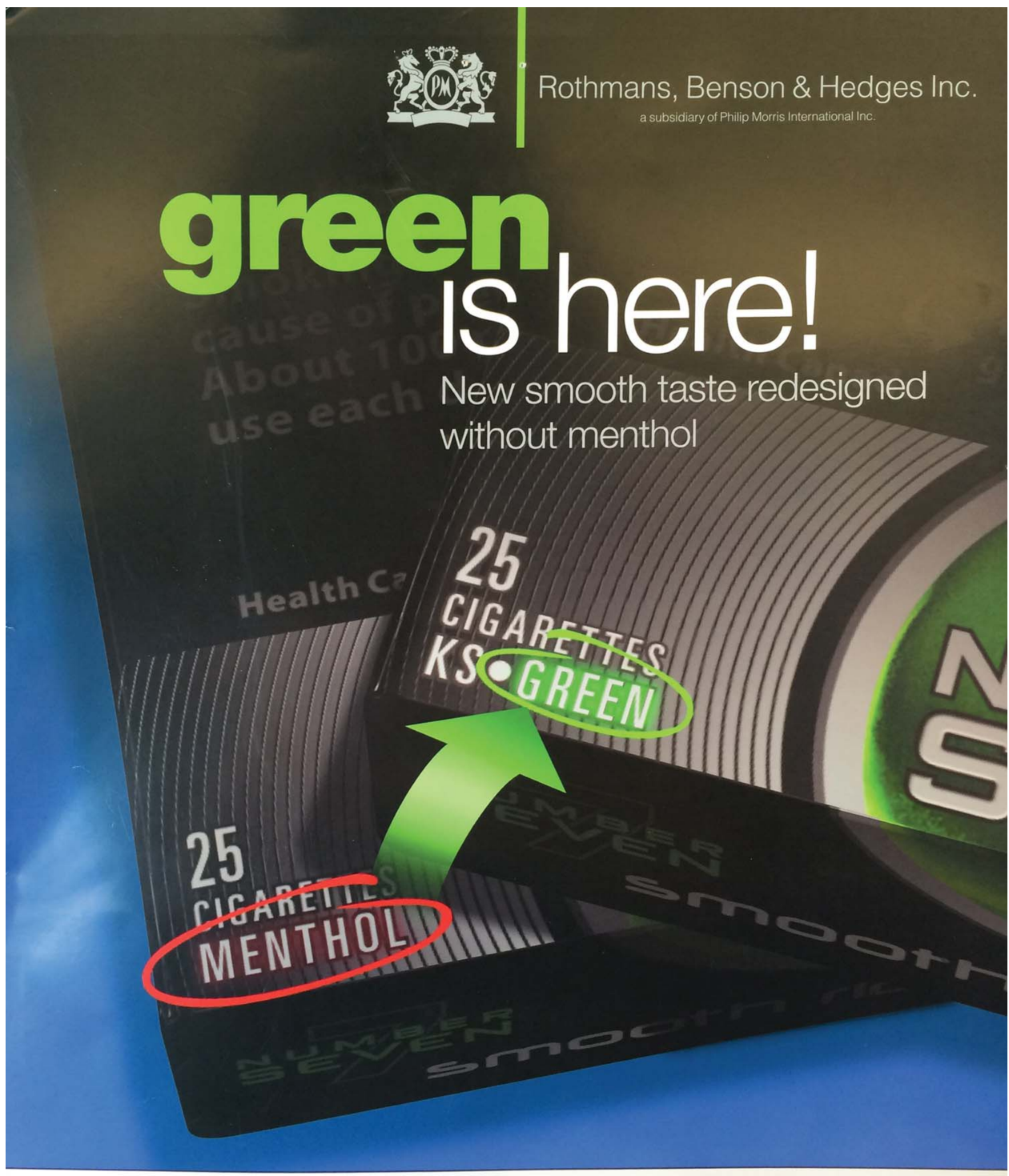

WARNING Tobacco smoke hurts everyone.

Infants who are exposed to tobacco smoke are at greater risk of dying from Sudden Infant Death Syndrome (SIDS). Health Canada

Figure 3 Business-to-business marketing materials from Rothmans, Benson \& Hedges (owned by Philip Morris International), demonstrating the shift to menthol replacement packs.

\section{CONCLUSIONS}

Similar to the industry response following removal of misleading descriptors, PMI has repackaged their products postban to communicate menthol-like flavouring using colour and substitution descriptors. This may potentially make it easy for retailers and consumers to identify their usual brand of cigarettes postban, allowing cigarette companies to market replacement cigarettes so as to create the impression that they continue to have the same characteristics as menthol cigarettes despite the sales ban. The redesign of menthol packs to connote 'smooth' taste and flavouring may undermine the public health benefits of the menthol ban. Not all tobacco companies had released menthol replacement packs, and the company that did had fewer brand variants of menthol replacement packs than original menthol packs. The smaller number of brand variants and the absence of two parent companies from marketing replacement packs, while difficult to interpret, may indicate the beginnings of market testing by tobacco companies, or conversely, might suggest that menthol replacement packaging may not become widespread.

Research on the impact of the ban on consumer behaviour and consumer reaction to the new 'green' cigarettes is warranted. These findings on the industry response in light of the world's first examples of implementation of a menthol ban should be considered as jurisdictions formulate policies to ban menthol tobacco products. To reduce tobacco industry tactics to circumvent restrictions on menthol, future policies should prohibit menthol in tobacco products as an ingredient and additive, prohibit marketing claiming menthol-like characteristics and prohibit marketing of menthol tobacco products.

\section{Twitter Follow Jennifer Brown at @jenniferlynette}

Acknowledgements The authors thank our team of data collectors and coders for their help, including Laura Kroart, Stephanie Ng, Adamove Osho and Kara Robinson. 
Contributors JB, TD, and JEC and KW contributed to conception and design, data collection, data analysis, data interpretation and article writing. RS, MC and DLK contributed to conception and design, data interpretation and article revision. All authors provided final approval for submission to Tobacco Control.

Funding This work was supported by a Lipitz Public Health Policy Faculty Award awarded to JEC.

Competing interests None declared.

Provenance and peer review Not commissioned; externally peer reviewed.

Open Access This is an Open Access article distributed in accordance with the Creative Commons Attribution Non Commercial (CC BY-NC 4.0) license, which permits others to distribute, remix, adapt, build upon this work non-commercially, and license their derivative works on different terms, provided the original work is properly cited and the use is non-commercial. See: http://creativecommons.org/ licenses/by-nc/4.0/

\section{REFERENCES}

1 Nonnemaker J, Hersey J, Homsi G, et al. Initiation with menthol cigarettes and youth smoking uptake. Addiction 2013;108:171-8.

2 Hersey JC, Ng SW, Nonnemaker JM, et al. Are menthol cigarettes a starter product for youth? Nicotine Tob Res 2006;8:403-13.

3 Hersey JC, Nonnemaker JM, Homsi G. Menthol cigarettes contribute to the appeal and addiction potential of smoking for youth. Nicotine Tob Res 2010;12(Suppl 2): S136-46.

4 Fernander A, Rayens MK, Zhang M, et al. Are age of smoking initiation and purchasing patterns associated with menthol smoking? Addiction 2010;105(Suppl):39-45.

5 Delnevo CD, Gundersen DA, Hrywna M, et al. Smoking-cessation prevalence among U.S. smokers of menthol versus non-menthol cigarettes. Am J Prev Med 2011;41:357-65.
6 Smith SS, Fiore MC, Baker TB. Smoking cessation in smokers who smoke menthol and non-menthol cigarettes. Addiction 2014;109:2107-17.

7 Okuyemi KS, Ahluwalia JS, Ebersole-Robinson M, et al. Does menthol attenuate the effect of bupropion among African American smokers? Addiction 2003:98:1387-93.

8 Pletcher MJ, Hulley BJ, Houston T, et al. Menthol cigarettes, smoking cessation, atherosclerosis, and pulmonary function: the Coronary Artery Risk Development in Young Adults (CARDIA) study. Arch Intern Med 2006;166:1915-22.

9 World Health Organization. Advisory Note: Banning Menthol in Tobacco Products. http://apps.who.int/iris/bitstream/10665/205928/1/978924/1510332_eng.pdf?ua=1 (accessed 25 May 2016).

10 World Health Organization. Partial Guidelines for Implementation of Articles 9 and 10 of the WHO Framework Convention on Tobacco Control. http://www.who.int/ fctc/guidelines/Guideliness_Articles_9_10_rev_240613.pdf?ua=1 (accessed 13 Feb 2016).

11 Tobacco Control Legal Consortium. How Other Countries Regulate Flavored Tobacco Products. http://publichealthlawcenter.org/sites/default/files/resources/ tclc-fs-global-flavored-regs-2015.pdf (accessed 12 Feb 2016).

12 Cohen JE, Yang J, Donaldson EA. Impact of the removal of light and mild descriptors from cigarette packages in Ontario, Canada: switching to 'light replacement' brand variants. Prev Med (Baltim) 2014;69:120-5.

13 Connolly GN, Alpert HR. Has the tobacco industry evaded the FDA's ban on 'Light' cigarette descriptors? Tob Control 2014;23:140-5.

14 Ford A, Moodie C, Purves R, et al. Adolescent girls and young adult women's perceptions of superslims cigarette packaging: a qualitative study. BMJ Open 2016;6:e010102.

15 Mir H, Buchanan D, Gilmore A, et al. Cigarette pack labelling in 12 countries at different levels of economic development. I Public Health Policy 2011; 32:146-64.

16 Government of Canada. Statistics Canada. http://www.statcan.gc.ca/tables-tableaux/ sum-som/101/cst01/demo02a-eng.htm 